\title{
Dinâmicas de espaço do road movie da década de 70: Richard C. Sarafian, Monte Hellman e Terrence Malick Filipa Rosário ${ }^{1}$
}

Em 1969, Easy Rider (Dennis Hopper) inaugura nos Estados Unidos o road movie, um género onde o espaço do western se cruza com o protagonista do noir, transformando-se ambos naturalmente no processo. Desse confronto, edifica-se um tempo pós-mítico que corresponde também, mas de uma outra perspetiva, ao pós-classicismo do cinema americano.

New Hollywood é o nome do movimento cinematográfico que surge quando uma certa ideologia pacifista revolucionária se manifesta na década de 1960, naquele país, sob a forma de contracultura. Robert Altman, Hal Ashby, Peter Bogdanovich, John Boorman, Michael Cimino, Francis Ford Coppola, William Friedkin, Monte Hellman, George Lucas, Terrence Malick, Sam Peckinpah, Arthur Penn, Bob Rafelson, John Schlesinger, Martin Scorsese e Steven Spielberg são alguns dos realizadores daquela geração que trabalha ainda dentro do sistema dos grandes estúdios, mas já com uma outra autonomia. Desta forma, os jovens realizadores puderam fazer um tipo de cinema que foi ao encontro daquilo que à época atraía o também jovem público e que o cinema produzido até então não oferecia. Pam Cook $(1985,100)$ descreve o movimento como um novo cinema aventureiro, responsável por fazer a ligação entre as tradições do cinema clássico de Hollywood e as inovações estilísticas do cinema de arte europeu. Noël Carroll, por seu lado, caracteriza-o como cinema de alusão:

a mix of a lot of practices including quotations, the memorialization of past genres, the reworking of past genres, homages and the recreation of "classic" scenes, shots, plot motifs, lines of dialogue, themes, gestures, and so forth from film history, especially as that history was crystallized and codified in the sixties and early seventies (1982, 52).

Grande parte dos autores e realizadores da New Hollywood foram educados e formados pelos filmes que viam, e, à época, o cinema de Jean-Luc Godard e de François Truffaut estreava nos Estados Unidos. Trata-se assim de uma geração de realizadores com grande cultura cinéfila, um amor declarado pelos clássicos, uma sensibilidade maior para com o cinema europeu e, acima de tudo, a intenção de trabalhar este cruzamento consolidado de influências. O modo de

\footnotetext{
${ }^{1}$ Universidade de Lisboa, Centro de Estudos Comparatistas, 1600-214 Lisboa, Portugal.
} 
pensar o cinema transforma-se, assim como o processo da sua construção. Agora, os realizadores são "autores": os seus filmes expõem mais concretamente a sua subjetividade. O período de instabilidade das produtoras e dos estúdios permitiu que a força criativa dos realizadores trabalhasse com maior liberdade. A crítica e o público, afeiçoado à televisão e às suas sitcoms escapistas, como All in the Family (Sklar 1976, 323), ganham curiosidade pelo novo cinema nacionacional, que ia ao encontro da sua sensibilidade e interesses.

A New Hollywood trabalha de um modo específico o tema da viagem enquanto estrutura narrativa - o road movie surge historicamente neste contexto. No que respeita ao seu funcionamento interno, o género desenha uma paisagem profundamente histórica a partir da personagem, criando, dessa forma, um tempo pessoal, íntimo e único, que tudo contamina: o próprio espaço e tempo do filme. Trata-se da dimensão mais relevante deste universo: a centralidade visual do elemento espacial a ecoar a impressão do tempo histórico na esfera da personagem, produzindo pelo confronto uma subjetividade. Ou seja, na paisagem reside o Tempo, e cabe à personagem construir o seu próprio tempo por meio da experiência dessa mesma paisagem.

Por seu lado, o perfil noir ${ }^{2}$ dos protagonistas do road movie mantém-se inalterado nesta fase da história do género, nunca deixando de ser uma personagem angustiada, vítima da lógica "distorcida" e "injusta" do mundo. É alguém para quem a independência e o isolamento são essenciais, acabando por sabotar ligações de apego e responsabilidade. De modo geral, o espaço é por ela encarado como ameaça. Isto é, o topos deste género, a cidade, é simbolicamente desenraizado no sentido de não se constituir enquanto lar - o espaço privado onde a identidade está salvaguardada e as autodefesas de cada um podem ser desarmadas - para os seus habitantes (Christopher 1997, 17). ${ }^{3}$ Desta forma, a nível temático, o

${ }^{2}$ O noir descende do filme de gangsters, como Little Caesar (Mervyn LeRoy, 1930), The Public Enemy (William Wellman, 1931) e Scarface (Howard Hawks, 1932), que surge com o sonoro e por reação à Lei Seca e à Grande Depressão. Daí que o realismo social fatalista que se encontra na base do género: o American Dream é o sonho inalcançável para as classes trabalhadoras, que conseguem obter dinheiro por via do crime. O protagonista do filme de gangsters está condenado a uma vida curta porque é rebelde, prescinde de um código moral conservador para romanticamente enveredar por uma trajetória arriscada e condenada (Hayward 2006, 154). Em todo o caso, a cidade surge aqui como cenário de violência, marginalidade e morte. O noir absorve esse traço da paisagem urbana, sendo que o protagonista que a habita, apesar de se encontrar do lado da lei - o gangster tornase detetive no noir por reação ao Código Hays, que condenava a mitificação do criminoso -, não se revê nela.

${ }^{3}$ Os espaços públicos e impessoais são o cenário da ação: diners, bares, discotecas, automóveis, ruas, becos, suites de hotéis luxuosos, apartamentos desconfortáveis. Locais de passagem - terminais de autocarro, estacões de comboio, mercados, hotéis e motéis - e espaços precários - telhados, viadutos, pontes, parapeitos de janelas altas, becos mal iluminados, comboios e carris de comboios - têm também uma importância maior. A cidade torna-se, então, num labirinto hostil onde a ameaça surge tendencialmente fora de casa, sublinhando desse modo a importância do 
género caracteriza-se por uma atmosfera generalizada de alienação, paranoia e pessimismo, assim como alguma ambivalência moral.

O road movie herda o perfil do protagonista noir, assim como esta experiência específica do espaço, sendo que o género da estrada opera dentro e sobre ele a vários níveis. À ideia de que a trajetória é definida em função da personagem, junta-se uma outra, que leva a que a ideologia do filme se complexifique. A personagem não abdica da relação com o asfalto e as suas margens, mas a dormência com que a ligação é vivida reprime possíveis interações com o viajante. A voz do realizador, através dos seus agentes, destaca-se da da personagem, e esta possível libertação - por vezes disfarçada - pode subverter a ideologia que a viagem simboliza.

Nas páginas que se seguem, serão analisados Vanishing Point (Richard C. Sarafian, 1971), Two-lane Blacktop (Monte Hellmann, 1971) e Badlands (Terrence Malick, 1973), três road movies que integram viagens distintas mas que, a dado momento, se assemelham. Fazem-no por via dos seus heróis, que agem como peregrinos nãomísticos para quem a viagem surge como um destino em si, mesmo se disfarçadamente. Neste sentido, compreendendo o modo através do qual personagens e realizadores contemplam e reagem ao cenário e à paisagem, torna-se possível discernir o ideário e a ideologia que a sua praxis parece não revelar.

Após a apresentação dos filmes escolhidos no contexto específico das lógicas de espaço, será exposta a oposição ideológica entre campo e cidade, e clarificado o lugar simbólico de cada uma das obras no âmbito deste mesmo contraste. Num segundo momento, Midnight Cowboy (John Schlesinger, 1969) e Alice's Restaurant (Arthur Penn, 1969) surgirão enquanto referências tutelares da dinâmica de espaço do road movie à época, para posteriormente compreender de forma esclarecida o modo como o campo é apresentado e habitado naquele momento da história do género. Por fim, serão referidos os gestos subversivos dos filmes face à experiência do espaço, tendencialmente moralizante ou moralizadora. Todo este percurso retórico invocará, sempre que necessário, o filme inaugural de Dennis Hopper, sendo que será também com ele que este percurso se iniciará.

\section{Paisagens sem relevo}

Easy Rider faz corresponder o exílio existencial no movimento ao pathos da personagem do road movie, ficando assim o espaço reduzido a cenário. O viajante retira-se para o espaço real e simbólico da viagem, sendo que deixa de haver contemplação na viagem; a autor-

planeamento urbano: o noir como tática da organização espacial metropolitana (Bruno 2002, 29). O género torna-se atmosférico pelo modo como, mesmo quando a ação tem lugar fora dos limites metropolitanos, a presença da cidade é invocada e sentida. 
realização da personagem esgota-se no percorrer da estrada, agora correspondência direta e seca entre trajeto e trajetória.

Protagonista e realizador não vivem o espaço da mesma forma. O final de Easy Rider ${ }^{4}$, que liberta a câmara da focalização interna com a qual o filme tende a alinhar-se, inaugura uma distância entre os dois, que os primeiros road movies desenvolvem. Vanishing Point, Two-lane Blacktop e Badlands funcionam sob essa lógica. São histórias cujas personagens são impelidas a fazer a viagem porque a estrada surge enquanto saída possível. A câmara segue a personagem numa tentativa de perceber o mundo, por via da experiência que esta tem dele. Ela dita o tempo e o espaço e, por esse motivo, ambos perdem alguma autonomia narrativa.

O filme tende para a personagem e a convergência nesta dá-se pelo modo como o realizador se projeta nela - a sensibilidade do filme é a sensibilidade da personagem. São muito pouco frequentes as cenas não focalizadas ou focalizadas externamente, o que fortalece a teoria de Elsaesser $(2004,286)$ segundo a qual a autocomiseração se apresenta como marca de estilo do cinema norte-americano dos anos 70 .

Tendo em conta esta dinâmica, o tratamento da paisagem rural e urbana - nos primeiros anos do género sofre do distanciamento com que a personagem se relaciona com ela. Em Vanishing Point, Kowalski atravessa o Colorado, o Utah, o Nevada, a caminho da Califórnia, quase sem paragens e sempre indiferente à paisagem. Mais, a contestação de Kowalski não se exprime na sua ligação à paisagem, mas sim na sua relação com as linhas da estrada: o Dodge Challenger de 71 de Kowalski ultrapassa os outros carros pelas bermas e campos que ladeiam a estrada, salta por cima de viadutos ainda em construção, para a marcha subitamente na faixa, investe pelo deserto, de onde se acredita não conseguirá escapar. $O$ nãoalinhamento com a ordem, a desobediência às regras do sistema, refletem-se no modo como vive a estrada e, assim, a paisagem que opera enquanto fundo da viagem fica reduzida a esse papel, não adquirindo relevância dramática. No limite, aspira pontualmente a uma abstração, que não se concretiza na sua totalidade.

Por seu lado, os protagonistas de Two-lane Blacktop não se revoltam, não lhes interessa prevaricar, antes acelerar. Numa narrativa

\footnotetext{
${ }^{4}$ Em Easy Rider, a estrada parece aberta, no travelogue final antes das mortes, ao som de It's Alright, Ma (I'm only Bleeding) de Bob Dylan. O desapontamento de Wyatt é exprimido e sublinhado pela banda sonora, momentos depois de ter exclamado We blew it. Um grupo de habitantes locais chegam pela direção oposta, fazem inversão de marcha, ultrapassam Wyatt e Billy e atiram sobre este, que cai, ferido. Wyatt coloca-se a caminho para chamar auxílio e, aí, é alvejado e projetado para a berma da estrada. A moto é atingida e incendeia-se; os assassinos seguem viagem. A câmara, que até aí permaneceu em todas as cenas do filme ligada a uma das duas personagens, liberta-se. Recorrendo à terminologia de Genette (1980), a focalização interna - alternadamente, fixa e variável - dá lugar a focalização zero.
} 
que resiste a um fechamento, não se dá qualquer tipo de desenvolvimento no percurso existencial da personagem. A trajetória de Driver e de Mechanic coincide na totalidade com o trajeto que fazem, circular e infinito. Para que essa identidade aconteça, a personagem não tem de se desenvolver, aprender ou redimir-se.

A viagem errática, imprevisível e sem fim despolitizou-se. A concretização pessoal de Driver e Mechanic passa apenas pelo ato de conduzir, manter o automóvel em movimento; as duas personagens identificam-se nesse objectivo. Elas percorrem parte dos Estados Unidos para participar em corridas, e nunca verbalizam nada que não esteja relacionado com a viatura ou com estas pequenas competições. Assim sendo, o espaço é encarado como superfície a ser a percorrida; a trajetória narrativa dos dois é um processo em curso, que terminará no momento em que a estrada acabar. Um movimento que Monte Hellman faz com que continue para lá do ecrã, quando, na cena final, os mecanismos formais do filme aderem à subjetividade da personagem - câmara lenta, som em off a desaparecer, som do motor a aumentar -, a imagem paralisa e a película do filme arde.

Two-lane Blacktop corresponde à concretização mais arriscada de uma ideia que Easy Rider cria e que Vanishing Point aprofunda. Esse risco - o distanciamento patológico e crónico do real -, transporta o road movie para um nível de alienação de tal forma poderoso que subverte a iconografia do género: (I) as estradas constituem o espaço onde o carro pode acelerar; (II) a paisagem "inspiradora" e simbólica define-se por envolver fisicamente a estrada; (III) motéis, diners, parques de estacionamento, bombas de gasolina - focos de energia urbana, de civilização - aceitam-se como parte do jogo, porque necessários.

Os protagonistas do road movie, depois de Easy Rider, deixam de estar interessados na descoberta da "América real", porque para eles ela não existe. A própria palavra "descoberta" deixa de fazer sentido naquele universo. A projeção épica de Monument Valley, que ainda resulta com Wyatt e Billy no filme de Hopper, não funciona para Kowalski em Vanishing Point, nem para Driver ou Mechanic em Two-lane Blacktop. A relação entre personagem e espaço no road movie, tal como é vivida na primeira fase da vida do género, é criada em Easy Rider, mesmo que os seus protagonistas não a tenham experienciado do mesmo modo.

Este gesto "traumatizado" leva a que, depois de Easy Rider, uma dimensão existencialista fique associada à motivação do protagonista. O ennui, a alienação, o absurdo, a liberdade e o compromisso, o nada estão permanentemente em jogo. Este distanciamento simbólico do real leva a que o espaço em Two-lane Blacktop seja uniforme. Nem as personagens, nem o realizador, atribuem juízos de valor ao rural e ao urbano - uma leitura nova da paisagem num género cuja primeira tendência passa por condenar a cidade e projetar na viagem 
no campo a possibilidade da autorrealização do indivíduo. O filme de Monte Hellman faz conviver a "imobilidade" psicológica dos protagonistas - as personagens não se desenvolvem - com a velocidade do movimento e devoção ao trajeto.

Desse equilíbrio existencial e quase absurdo renasce a personagem on the road: a sua motivação é reconstruída, recuperada, a partir das paisagens interiores devastadas que Two-lane Blacktop apresenta. ${ }^{5}$ Este funde, no mesmo plano, a cidade com o campo. Fálo, retirando-se da dinâmica específica entre indivíduo e espaço que Easy Rider pretende recuperar do western, isto é, afasta a contemplação da relação, reduzindo a autorrealização da personagem à ininterrupção da viagem.

\section{Personagem e viagens}

A complexidade da relação entre a cidade e o campo é exposta no género com Two-lane Blacktop. Monte Hellman tende a alinhar-se com a personagem e os primeiros road movies tendem a ser focalizados internamente. O filme, que resiste a ser focalizado, homogeneiza o espaço pelo modo como a câmara perde o acesso à motivação da personagem e, reduzida a filmar a ação, ela capta a natureza na relação "descomprometida" e física entre personagem e espaço.

Se a cidade e o campo são apresentados como elementos complementares do espaço, a viagem define-se, então, como reflexo condicionado, impulso que se liga a uma memória histórica, arquetípica e mítica - impulso esse que se encontra na base dos Estados Unidos enquanto nação. O passado do protagonista do género passa, como foi já mencionado, pelo western, cujo herói é o homem da fronteira que percorre o território para o conquistar, mediando o espaço entre a wilderness e a civilização, mundos que domina mas aos quais não pertence exclusivamente (Schneekloth 1996, 214). A dormência que Two-lane Blacktop imprime a esta dinâmica não a anula: subverte-a, esvaziando-a. Agora, a questão não é tanto a da pertença: a personagem exilou-se, mas não prescinde da ligação física à paisagem. Portanto, de alguma forma, ela pertence ao espaço que a acolhe. O que aqui surge como novidade é o facto de a personagem ter encontrado uma nova margem onde habitar - a estrada apresenta-se a Driver como lugar familiar: uma casa.

A paisagem tornou-se vazia, no sentido em que, sem a contemplação, sem o olhar consciente, pensativo, quase deferencial de quem observa, ela cessa de existir enquanto tal Mas a cidade e o campo revelam territórios diferentes, representam forças distintas.

\footnotetext{
${ }^{5}$ Paris, Texas (Wim Wenders, 1984) é o road movie que trabalha essa motivação, confrontando-a com o desejo de redenção do viajante (Rosário 2009) e definindo retroativamente o intervalo de tempo entre 1969 e 1984 como a primeira fase da história do género.
} 
Complementares, são espaços ocupados segundo lógicas diferentes o campo permite percecionar a terra abstratamente, apesar de nela estarem presentes formas de ocupação e transformação, de progresso; a cidade funciona em si mesma como uma forma de ocupação de transformação da terra porque a cidade "é" progresso. Easy Rider trabalha a partir desta distinção, distorcendo-a e amplificando-a. O road movie, enquanto descendente dos filmes de viagens, invoca a demanda como motivação, sendo a viagem a exteriorização dessa vontade.

O ideal pastoral, no sentido da ligação do homem à terra, corresponde, na personagem que viaja, a um regresso às origens primordiais do ser. Trata-se de algo que transcende a natureza economicista do sistema, sendo igualmente possível que este possa integrar indícios de um desejo de subversão. A imagem do campo, da wilderness, da natureza intocada e selvagem, tem a conotação específica de princípio do mundo, de alguma inocência e de toda a possibilidade de autoconcretização. Tendo em conta este quadro, a viagem torna-se num gesto nostálgico. Wyatt e Billy seguem os passos dos seus antecessores, neste sentido concreto. Kowalski, Driver e Mechanic, por outro lado, obliteram a dimensão "revisitacional" da viagem, levando a que o sentido histórico seja bloqueado.

Em todo o caso, a força mítica do movimento impõe-se, mesmo que as personagens não o reconheçam. É precisamente desse conflito - a viagem mitificadora contra o achatamento emocional e o pathos de insucesso, utilizando a expressão de Elsaesser $(2004,284)$ - que Vanishing Point e Two-lane Blacktop se constroem, resultando daí uma postura cool, blasé, mas obstinada face à estrada.

O road movie, enquanto descente direto do western, integra uma dinâmica que Ralph Willet descreve da seguinte forma:

Space and landscape bestow on action an epic dimension, and also encouraged what Robert Warshow has described as 'moral openness'. This type of setting provides for a moral dialectic and primitive conflict that are satisfyingly straightforward to the troubled urban man $(1970,456)$.

O género integra essa distinção específica entre campo e cidade. Esta "complementaridade conflituosa" aponta para um dos pressupostos em que o género assenta, para depois o desconstruir.

Quando Raymond Williams (1973) refere que a tendência do indivíduo para moralizar sobre a oposição espaço rural/espaço urbano surge da necessidade da resolução de uma tensão concreta, o historiador identifica a problemática ideológica que molda o comportamento do protagonista do género. O campo está associado ao passado e a cidade ao futuro, levando a que o presente instaure no indivíduo a indefinição ontológica, existencial. Mais, dado que o herói on the road é marginal, o presente torna-se um momento do qual ele se retira, ou com o qual joga: a velocidade é disso sintoma e expressão. 
Ainda analisando a questão do campo enquanto ideia de passado trabalhada pela memória, as imagens que Raymond Williams convoca cristalizam-se no sujeito:

not only the local memories, or the ideally shared communal memory, but the feel of childhood: of delighted absorption in our own world, from which, eventually, in the course of growing up, we are distanced and separated, so that it and the world become things we observe $(1973,297)$.

A assunção de que ao rural se associam juízos simplistas porque simplificados - , e leituras autocentradas do mundo opera enquanto princípio basilar da motivação de Wyatt e Billy, os primeiros heróis do género. Para eles, a viagem é um gesto nostálgico. Mas não é apenas a motivação que ilustra a infantilidade que Raymond Williams refere. Os seus nomes, que invocam um passado histórico mitificado, aplicam e aprofundam a lógica - Wyatt Earp e Billy, The Kid querem regressar a um passado concreto e impossível, ao "tempo dos cowboys". Em todo o caso, existe no protagonista do género, como no do western ou, de um modo geral, no fora-da-lei, a resistência à adaptação ao novo.

O juízo moral que a personagem aplica aos espaços aparece concebido em função de um jogo psicologizante, que não permite analisá-los objetivamente, ou seja, fazer a leitura dos processos sociais reais de alienação, separação, externalidade e abstração que poderão concluir onde se encontra a "verdadeira” deformação (298). A fantasia - a nostalgia de um passado construído pela memória e alimentado retroativamente pelo mito - mascara-a. E aqui o papel do mito é essencial pelo modo como, no road movie e através do western, estão em jogo construções de um passado violento, desde sempre mitificado e romantizado, assim como construções arquetípicas sobre as origens do Homem associadas ao espaço selvagem.

A tensão intensifica-se na urbe. Wyatt e Billy, os heróis de Easy Rider, retiram-se da cidade por acreditar que a "América real" está fora da cidade. Ou seja, que as redes sociais, de informação, de transportes - todas as estruturas organizativas, burocráticas que arrumam o espaço e padronizam, rigidificando, o comportamento humano -, contaminam e minam a possibilidade do desenvolvimento, autoconhecimento e autorrealização do homem. Creem que só fora da cidade seja possível encontrar algo mais "verdadeiro", "longe da civilização".

A mesma questão parece estar presente em Kowalski mas subvertida, no sentido em que a motivação dos primeiros se liga à demanda e, no herói de Vanishing Point, ela coexiste com a fuga. A viagem de Kowalski adquire, em movimento, o estatuto de escape, que, por ganhar proporções improváveis, se torna épica - a viagem ganha um nível simbólico on the road. Aí, a fuga transforma-se numa competição, numa corrida que aponta na direção do fim da estrada, o 
ponto de fuga para o qual o título do filme alerta. Poder-se-á falar de demanda: simbólica, impossível, utópica - a fronteira enquanto espaço abstrato.

O suicídio do protagonista encontra-se encenado enquanto ato último de liberdade e é experienciado desse modo pelo espectador, pois o filme constrói-se em crescendo. Super Soul, o DJ de rádio que intercepta na sua estação a frequência do sinal de comunicação da polícia, acompanha a perseguição de Kowalski, comentando-a. Dessa forma, é a voz que pontua a narrativa e que influi na heroicização do protagonista, promovendo-o como o last American hero. As cenas internamente focalizadas através de Super Soul funcionam também nesse sentido, para além de introduzirem na narrativa a sua banda sonora, que, no filme, começa por pertencer ao som diegético. A personagem, violentamente agredida pelos locais, depois de mitificar Kowalski no seu programa de rádio, transforma-se também numa vítima do sistema contra o qual o herói se insurge. A viagem de Kowalski torna-se simbólica depois de ter tido início, o que implica que a dimensão existencial do movimento surja na estrada, pois é ela que concretiza uma tendência que até aí não se havia manifestado.

A alienação de Driver e Mechanic que conduz à amoralização do espaço permite analisar a questão do exílio no movimento, a nova margem, o novo "inter-territórios" para onde se retiraram. Novamente, aqui ressalta a ideia das personagens enquanto crianças perdidas no seu prazer, que "brincam" concentradas totalmente no gesto, no momento. O exílio voluntário, enquanto plataforma de negociação do espaço da personagem em sociedade, é o tema central do road movie. Este poderá cruzar-se com outros motivos, como a possibilidade da concretização dos afetos ou a possibilidade da liberdade.

A viagem é a exteriorização da paisagem interior da personagem. A viagem é possibilidade. Em Two-lane Blacktop, o ponto de fuga é o destino dos dois protagonistas, mas a questão essencial do road movie está menos no destino da viagem do que na sua experiência concreta. De tal forma que, neste filme, o espectador não tem acesso aos nomes das personagens, elas são identificadas através da função que representam na história, na viagem: o condutor, o mecânico, a rapariga e o GTO, a personagem masculina mais velha que conduz o modelo Pontiac homónimo. Todos surgem reduzidos à fisicalidade do trajeto: as corridas de carros em que participam não esgotam o desejo de competição na estrada.

Os dois protagonistas resistem à focalização interna (Lefebvre 2001, 153). GTO, o contraponto deles, "humaniza" a viagem - também errática, absurda e vital - , pelo modo como adere ao estilo de vida de Driver e de Mechanic sem deixar de verbalizar a necessidade de parar. GTO mais velho que eles e à deriva pelo país poderia funcionar como figura paternal ou projeção dos dois no futuro, mas a personagem foge às correspondências. Num universo em que as per- 
sonagens não comunicam, só conduzem, ele mente compulsivamente, dá boleia a estranhos pela companhia, apresentando a cada passageiro versões diferentes da sua trajetória. GTO é a personagem que impõe, no filme, a focalização interna fixa, ao comentar a sua angústia. Para além disso, na sua última cena, GTO esclarece sobre o modo de vida dos dois protagonistas: "But I'll tell ya, there's nothin' like building up an old automobile from scratch and wiping out one of these Detroit machines. That gives you a set of emotions that stay with you. You know what I mean? Those satisfactions are permanent".

GTO expressa o que eles, Driver e Mechanic, não conseguem. O filme, nas cenas em que estes estão presentes, tende para a focalização externa. Mesmo que se compreenda a motivação dos dois em episódios pontuais, como quando se combina uma corrida, não é dada mais informação, para além da que se refere à ação num momento específico. Quem explica ao espectador que, com dificuldade, tenta compreender o que move os dois é GTO, por estabelecer a relação entre o universo privado dos dois e a realidade. Consciente da implicação daquela dinâmica alienante, GTO afirma: "You probably didn't suspect that but it's all I can do just to keep moving. I get uptight just thinking about tomorrow. [...] We'll build a house, that's what we'll do. We'll build a house because if I'm not grounded pretty soon I'm going into orbit". A viagem não é "solução" para a ansiedade desta personagem, que sabe que se encontra num limbo perigoso.

Após o discurso de GTO sobre as satisfações permanentes que justifica também a viagem interminável dos dois protagonistas, a câmara alinha-se com Driver no momento da última corrida. O crescendo final, que mitifica a velocidade e o condutor, - (I) a câmara filma a linha divisória da estrada; (II) o som desaparece; (III) barulhos mínimos ecoam no espaço quase claustrofóbico da mente de quem conduz o carro; (IV) Driver observa atento a indicação da partida da corrida; (V) a velocidade do filme abranda-, mostra como a câmara/o filme entram finalmente na esfera da personagem. A câmara entrega-se à lógica da personagem, obstinada e obcecada.

Two-lane Blacktop foca o drama interior das suas personagens, reduzido a um relevo emocional mínimo, contido, interiorizado. As personagens vivem o cenário de uma forma utilitarista e seca e, por contiguidade, o filme que quer compreender o mistério que elas contêm procede ao mesmo tratamento paisagístico. $\mathrm{O}$ espaço torna-se palco, que integra reminiscências míticas culturais por via das referências que o espectador domina e que não são efetivamente concretizadas pelo filme.

No desenvolvimento do road movie, o distanciamento entre personagem e espaço dá-se com o filme de Monte Hellman e no encalce de Easy Rider e Vanishing Point. Em todo o caso, as personagens não têm de rejeitar uma trajetória convencional ou de se afastar de 
um registo melodramático na expressão da sua interioridade para que o espaço seja (I) paisagem como Martin Lefebvre a define (2006, $51)^{6}$ e (II) palco/cenário dos dramas das personagens. Ou seja, personagem e espaço assumem-se como elementos autónomos que se podem diluir um no outro. O risco dessa contiguidade específica traduz-se na transferência da responsabilidade da ação da personagem para o espaço circundante. Esta implica um movimento de libertação, uma conquista de autonomia por parte daquela personagem. $\mathrm{O}$ road movie esconde-se por detrás desta dinâmica viciada.

\section{Viagem, cidade e civilização}

Stephen Farber (1969-1970) chama a atenção para o facto de a viagem surgir com frequência no cinema da New Hollywood, precisamente no ano de Easy Rider. Midnight Cowboy e Alice's Restaurant comprovam-no, expondo também modelos diferenciados de negociação entre a motivação e ação da personagem e o espaço geográfico e concreto em que se movem.

O filme de Schlesinger acompanha a viagem de Joe Buck Texas, Nova Iorque, Florida - , centrando-se fundamentalmente na permanência na cidade grande, onde Joe não concretiza as suas fantasias infantis, mas faz um amigo doente, Ratso. A Florida torna-se no lugar onde as fantasias deste se poderão concretizar e Joe leva-o, num gesto redentor que se concretiza efetivamente, apesar da morte de Ratso à chegada a Miami na última cena do filme. Midnight Cowboy apresenta a cidade grande como território do mal, contaminada pela decadência moral e física, habitado por monstros urbanos, que nela se transformam por ação direta do espaço; tudo aquilo que é de Nova Iorque está sujo e doente, como Ratso. O filme é internamente focalizado através das duas personagens, sobretudo de Joe: é com ele que o filme abre e fecha, é o centro da realidade retratada. Ratso pertence a essa realidade, assim como a cidade. A câmara nunca se afasta do protagonista. O espaço condena a personagem segundo a leitura que Schlesinger faz de Nova Iorque, e as personagens não se revoltam contra essa castração: têm a sua trajetória redentora mas não se autonomizam, não oferecem resistência ao espaço esmagador. Aqui, o espaço repele. Schlesinger impõe um espaço desta natureza, sacrificando desse modo a trajetória da personagem.

\footnotetext{
${ }^{6}$ "Landscape [...] is a representation of space. It is a form of spatial predicate. Another way of saying it would be to say that landscape is a form of being of external space in our minds. This representation, or sign, manifests itself in different ways. It manifests itself in the way that human beings visually apprehend some stretch of real space; in the way that they have of apprehending the space depicted in pictorial works of art; and in the way that some of these works have of "translating" this sign into specific pictorial compositions. In the domain of art, landscape in not so much the result of a work; rather, it is the work itself which is the result of the landscape. Thus, landscape manifests itself in an interpretive gaze" (Lefebvre 2006, 51).
} 
Easy Rider e Midnight Cowboy desresponsabilizam os seus heróis do mesmo modo: transferindo forçosamente para o espaço a obrigação de preencher o vazio da nostalgia de um "tempo" mítico. Mas, se Joe Buck é desculpabilizado pelo filme, que o apresenta como estranho homem infantilizado e traumatizado, Wyatt e Billy são celebrados nessa sua "façanha".

Alice's Restaurant comunica mais diretamente com o filme de Hopper: "Arlo is searching for freedom, and like the motorcyclists in Easy Rider, he expects to find it on the road, away from the city" (Farber 1969-1970, 10). Penn realiza este filme dois anos depois de Bonnie and Clyde, mas abdica da sua violência explícita e estilizada ao retratar a trajetória de Arlo, cicerone privilegiado da realidade cultural e histórica de $1969 .^{7}$

Alice's Restaurant não mitifica as suas personagens, apresentaas sim na sua complexidade psicológica, associando-as a um símbolo organizacional da contracultura, a comuna. O filme adota uma estratégia que se distancia da de Peter Fonda e Dennis Hopper, como Paul Schrader aponta (1990, 33-37). Arlo Guthrie, filho de Woody Guthrie no filme e na realidade, é o protagonista do filme, que aprofunda com outra seriedade a questão da demanda: a personagem - um jovem hippie de cabelos longos, cantautor folk -, constrói a sua trajetória individual on the road. E fá-lo autonomamente, no sentido em que não condescende na tentação de ligar o mal à small town ou à cidade grande.

O filme, através de Arlo, alterna entre cenas na cidade e cenas na vila: Nova Iorque, onde ele mora e onde o pai se encontra em estado terminal, e Stockbridge, no Massachussets, a small town onde se situa o restaurante de Alice. Internamente focalizado através de Arlo, a película atribui a outras personagens - Alice, Ray, Shelly e Obie -

\footnotetext{
${ }^{7}$ Bonnie and Clyde interessa também neste contexto. A relação das personagens do filme de 1967 com a paisagem define-se sobretudo pelo modo como vivem o espaço do automóvel. O gang convive dentro da viatura de um modo particular: viaja, foge, todos dormem e comem dentro do automóvel. Por serem foras da lei, dependem dele para sobreviver. Poder contar com o veículo como espaço da prática dos rituais quotidianos revela a sua versatilidade narrativa, e dilui a intensidade do impacto do espaço e do Outro na personagem. A imagem imortalizada de Bonnie e Clyde, fixada na infantil sessão fotográfica, inclui, para além dos próprios, as armas e o carro: tudo isto constitui a sua identidade. E tal como acontece em They Live By Night (Nicholas Ray, 1948), a vivência constante, intensa e partilhada da viatura pelo casal sacraliza-a, mitificando o automóvel A paisagem é, dessa forma, apropriada: a natureza torna-se no lar das personagens. Conversas íntimas e o encontro com a família de Bonnie, cenas familiares essenciais na narrativa, dão-se ao ar livre: a privacidade encontra-se no espaço aberto e a natureza aparece resacralizada. A validação do estatuto sagrado da paisagem natural é feita pela câmara e, contiguamente, pelo espectador, que com ela se alinha. Easy Rider, que também valida a natureza selvagem enquanto espaço "santo", fá-lo por uma via diferente: o mito enquanto herança cultural genética. Em Bonnie and Clyde, há uma relação original com o espaço, a natureza e a paisagem, vivida fisicamente, no momento - daí que o sagrado surja.
} 
trajetórias específicas, independentes da do protagonista. E são estes os responsáveis pelo fracasso da comuna, no fundo, o fim do sonho da contracultura, testemunhado por Arlo e pelo espectador, distanciados de formas diferenciadas daquela dinâmica.

As cenas que poderiam proceder a um tratamento moralizador do espaço - em Nova Iorque ou em New England -, fixam-se na ação das personagens, a quem não interessa julgar. São cenas de exterior que não integram o céu; a câmara está sempre apontada na direção do campo de visão das personagens. A contemplação do espaço fica assim anulada, não querendo com isto afirmar que as personagens não o valorizem. O estilo de vida dos membros da comuna é pastoral no sentido em que procedem a uma apropriação física e festiva do espaço; existe também uma liberdade no movimento que corresponde à sua vivência concreta e total, e que se traduz também pela celebração desse mesmo espaço.

A small town funciona, por seu lado, como palco da recriação do campo na cidade, no sentido em que a comuna é um projeto teoricamente autossustentável, que pretende fundir a vivência urbana com a rural. Porém, não só a sociedade civil a rejeita - a história que já o tema musical de Arlo Guthrie contava em Alice's Restaurant Massacree (1967) - , como se revela internamente doente, incapaz de oferecer soluções.

Alice's Restaurant critica o sistema e o antissistema sem desvalorizar nem a trajetória do herói, que na viagem toma conhecimento do "mundo", nem os espaços que atravessa. Easy Rider, no mesmo ano, faz o inverso.

Easy Rider, Vanishing Point, Two-lane Blacktop lidam com o espaço urbano e rural de modos distintos. Em conjunto, refletem um distanciamento crescente em relação ao espaço. Este, por sua vez, espelha a autoexclusão destes heróis, assim como as dicotomias cultura/contracultura, lei/fora da lei. Ou seja, representam uma outra ordem, que encontra espaço e expressão na estrada. Longe de lutas políticas, a viagem que os três filmes compõem torna-se gradualmente mais existencial, pelo modo como o espaço adquire contornos mais expressionistas que ideológicos. A paisagem torna-se cenário, um plano visual sobre o qual o movimento se concretiza. Contudo, a dimensão mítica do espaço norte-americano e da própria viagem não surge totalmente obliterada; resiste, minimizada. Esta resistência é acordada e reforçada pela banda sonora ou por outras personagens, Super Soul em Vanishing Point e GTO em Two-lane Blacktop. Deste modo é testada a força dos protagonistas, que se revelam solidamente empenhados no seu trajeto e trajetória. Driver corresponde, neste ângulo, à mais objetiva concretização da resistência alienada e solitária. É a personagem que com maior obstinação aponta para o ponto de fuga, que dá o sentido à sua existência. 


\section{O campo}

Badlands destaca-se da linha evolutiva que Easy Rider, Vanishing Point e Two-Lane Blacktop desenham entre si. A primeira obra de Terrence Malick pertence a uma outra linhagem do género, que encontra em Bonnie and Clyde a sua maior referência, a par de Gun Crazy (Joseph H. Lewis, 1950) e They Live by Night, entre outros. O neo-noir, que herda os temas e a sensibilidade do noir, abandona a estética a preto e branco e o jogo de contrastes entre luz e sombra, trabalhando sobretudo a alienação, o pessimismo, a ambivalência moral e a desorientação na esfera de motivação e ação da personagem (Conard 2007, 4). Gun Crazy e They Live by Night fazem parte do cânone que dará origem ao neo-noir e este, por sua vez, integra Bonnie and Clyde e Badlands. ${ }^{8}$ No que respeita às dinâmicas de espaço na primeira fase da história do road movie, o filme de Malick vem expor um distanciamento simbólico novo na relação entre a motivação e ação da personagem e a forma como o realizador as retrata.

A história de amor entre Kit e Holly começa na rua onde a jovem mora com o pai, num cenário idílico de uma rua banal numa small town. Holly joga com um bastão em frente da casa - a invocar American Gothic (1930), o quadro de Grant Wood -, quando Kit se aproxima, atraído por aquela imagem de perfeição e inocência. Musica Poetica de Carl Orff intensifica a simplicidade e ingenuidade do quadro, contribuindo para a construção da imagem bucólica e facilitando o alinhamento do espectador com Kit. Mas a força do título do filme influi na leitura da breve cena e o espectador não consegue esquecer-se de que o mal surgirá na trajetória das personagens. Os jovens apaixonam-se e, contra a vontade do pai de Holly, envolvemse.

Holly narra em off a história. Como é habitual no universo de Malick, o jogo de forças entre agentes narrativos é dinâmico, imprevisível e criativo. A voz off monótona de Holly procede a uma leitura infantilizada e não realista do mundo. A personagem verbaliza análises pouco lógicas das situações: uma vez mais, uma certa autocentralidade na perspetivação do real num protagonista do género. Mas a estranheza e a imprevisibilidade de Holly ultrapassa esse lado infantil. ${ }^{9}$

A história do filme é contada em retrospetiva por uma adolescente omnisciente mas alienada, e a câmara permite que o espectador

\footnotetext{
${ }^{8}$ No contexto do road movie, o neo-noir tem uma descendência própria que, sobretudo nos anos 90, adquiriu um dinamismo acrescido com as estreias de True Romance (Tony Scott, 1993) e Natural Born Killers (Oliver Stone, 1994).

${ }^{9}$ Por exemplo, quando refere o único motivo possível que poderia ter conduzido ao fim do período idílico do namoro: o facto de ter enterrado o peixe doente no quintal da casa. O sentido de causalidade em Holly é deturpado, o que leva a que a sua narração no filme adquira com frequência, o estatuto de comentário inesperado e, desse modo, adiciona-se um novo nível de informação a cada cena, mesmo que inconsequente.
} 
aceda diretamente aos acontecimentos a que ela se refere na narração. Contudo, a câmara revela ter uma consciência autónoma que se reflete na gradação dos planos e nos movimentos, instaurando uma nova distância. ${ }^{10}$

A câmara, no início da longa cena que evoca a viagem de barco de Mónica e o Desejo (Sommaren med Monika, Ingmar Bergman, 1953), onde a inocência, a infantilidade e um futuro feliz parecem possíveis e em harmonia, age de acordo com as palavras de Holly: ilustra-as através de uma sucessão de planos de pormenor de tudo a que ela se refere. A focalização interna fixa da cena intensifica-se com o detalhe dos planos encadeados: a imagem segue a palavra proferida e, juntas, concorrem num só significado: a exaltação da wilderness pela disponibilidade de recursos e liberdade que oferece a possibilidade da concretização da felicidade. ${ }^{11} \mathrm{Ou}$ seja, a referência mítica maior que todos os protagonistas do género partilham.

Na cave da casa, Kit escondeu o corpo do pai de Holly, ameaça maior à relação entre os dois. Depois do horror da primeira morte a única pela qual Kit admitirá sentir remorsos -, e do fogo apresentado como um Inferno, surge a wilderness sob a forma de água. Malick não condena as suas personagens porque não as julga: num momento são monstros diabólicos, logo se transformam em crianças sem necessidade de redenção - "livres". Os protagonistas têm o mal em si, mas a narrativa é apresentada de um modo relativizante.

Kit e Holly atravessam espaços distintos, por vezes contaminando-os no caminho. O espectador tem acesso ao modo como o casal percepciona o mundo mas está sempre fora da dinâmica: "In fact, they form part of the phenomena that challenge us" (Johnson 1974, 44). O filme não tece juízos de valor sobre o campo ou a cidade - palco das relações e tensões humanas cuja complexidade, profundidade e drama aparecem invocados criativamente por Malick ${ }^{12}$, e

\footnotetext{
${ }^{10}$ A lógica por detrás desta dinâmica resulta complexa e surpreende: Malick deixa o espectador encontrar o seu próprio sentido no mundo que apresenta, ao reunir nas mesmas cenas significados que apontam para diferentes direções. São níveis que interagem mas não se anulam, fortalecendo a ideia quando apontam no mesmo sentido. Quando Kit e Holly se retiram da civilização, para viverem escondidos na wilderness, a rapariga descreve a relação dos dois com a natureza, explicando como cada ramo, cada folha foi utilizado para montar a casa na árvore ou construir utensílios.

${ }^{11}$ A banda sonora da cena - a já mencionada composição de Orff, que pontua o filme nos momentos de inocência e aparente pureza -, enfatiza a alegria e o prazer genuíno das personagens na construção da vida na wilderness. Momentos felizes que ocorrem depois de ambos terem pegado fogo à casa gótica que, tal como no quadro de Wood, pertencia ao pai e à sua filha.

${ }^{12} \mathrm{O}$ jogo extraordinário de sentidos que Badlands revela, sobretudo tendo em conta a questão da representação de uma paisagem rural mitificada, o ideal pastoral, é desenvolvido por Malick em Days of Heaven (1978). Não sendo um road movie, o filme tem como tema central o movimento em todas as suas formas: humana, natural e mecânica - o movimento no espaço e o movimento do tempo, do progresso e da viagem. O efeito relativizante da orquestração fílmica de Malick em Days of
} 
localizados num espaço distinto, estranho ao cinema de Hollywood. Assim, não interessa tanto que os protagonistas sejam fora-da-lei, mas sim o modo inovador de conceber e contar a história que, por esse motivo, se distancia mais de Bonnie and Clyde do que aparenta. Essa é a façanha maior de Badlands.

\section{O mal e o bem}

O road movie faz relacionar o comportamento da personagem com o espaço que ela atravessa, por vezes forçando a ligação ao atribuir-lhe causalidade.

Se Badlands corresponde à libertação da personagem de uma lei moral, construída artificialmente pelo realizador e por ele imposta, Two-lane Blacktop traz ao género personagens que rejeitam a dinâmica que essa lei moral valida. Driver e Mechanic resistem à focalização, escondem em si a sua motivação, e o filme conta a história dessa resistência. $\mathrm{O}$ jogo de forças surge como ganho pelas personagens, e realização e montagem entregam-se a elas no momento final da história. Driver e Mechanic são de tal forma refratários que se insurgem dentro da lógica do género, em que a natureza da paisagem em articulação com o conceito de liberdade dita o comportamento da personagem.

Two-lane Blacktop assume a responsabilidade pela libertação por parte da personagem de um esquema narrativo que tende a absorvê-la e a vitimizá-la. Trata-se de uma liberdade conquistada pela própria personagem e só possível depois de se apreenderem as trajetórias de Wyatt, Billy e Kowalski. Badlands, que é posterior, assume essa libertação por parte de Driver e Mechanic e, paralelamente, responsabiliza os seus protagonistas ao não justificar ou julgar a

\footnotetext{
Heaven adquire outros contornos, uma vez que o drama humano se encontra diluído na paisagem. Isto é, as cenas focalizadas através das personagens apresentam a ação, que decorre num espaço tão ou mais importante que a própria personagem. A natureza encontra-se mitificada, quer pela relevância dada ao bestiário - gafanhotos, galinhas, cavalos, pavões, coelhos convivem com os humanos lado a lado, todos habitantes do mesmo território - , quer pela citação direta de quadros que dramatizam a relação entre o campo e a personagem - Des Glaneuses (1857) e Angelus (1857-59) de Jean-Francois Millet; Noon: Rest from Work (After Millet) (1890) de Van Gogh; House by the Railroad (1925) de Edward Hopper; Christina's World (1948) de Andrew Wyeth; Le Blanc-seing (1965) de René Magritte aparecem absorvidos por Days of Heaven. Resulta daí que o ritmo do filme, a sua respiração, se defina em função de uma tensão entre duas forças, a narrativa e a descritiva, que Malick apresenta enredadas, interdependentes e, novamente, relativizantes. Days of Heaven dilata os motivos de Badlands, aprofundando a questão do mal e do bem na personagem, em conjugação com uma determinada experiência do espaço e fá-lo pela alternância entre intensificação e descompressão da projeção dos efeitos dramáticos no espectador. Os planos de animais ou as reconstituições e citações de quadros, os momentos mortos que Martin Lefebvre aponta (2006, 40), funcionam nesse sentido: abrandam o ritmo da ação, permitindo a contemplação da imagem por parte do espectador.
} 
presença do mal neles. De Kit e Holly não se sabe muito, para além do que a imagem mostra e do que a jovem poderá partilhar na narração em off. A trajetória do casal assassino decorre como um processo definido em função de algo que a câmara mostra, não há um projeto maior a ser concretizado no movimento. Ou seja, nem o passado, nem a psicologia, importam em Badlands - as personagens são criminosas porque cometem crimes, e não porque estão traumatizadas. Importa sim, no filme, a apreensão da história enquanto universo integrador de sentidos vários, como já se afirmou.

Portanto, se Two-lane Blacktop rejeita moralizar o espaço rural e urbano - a personagem está consciente de que depende dos dois , em Badlands, a questão tão pouco se coloca: Holly e Kit são levados a sair dos espaços urbano e rural não porque os rejeitem, mas para sobreviver. Num género que tematiza a liberdade, mas que condiciona, aprisionando, a trajetória da personagem, Monte Hellman e Terrence Malick assumem-se como responsáveis pelas suas mais importantes libertações. A personagem impõe a sua lógica ao mundo apresentado, no primeiro caso. E, no segundo, o realizador, que respeita a individualidade da personagem, relativiza as diferentes lógicas do mundo e apresenta-as nessa sua condição relacional.

Tratam-se de sucessivas conquistas de autonomia narrativa por parte da personagem - e realizador - levando a que o género adquira uma maturidade nova e a que a essência da aventura do road movie ocorra, a partir de agora, numa geografia reconfigurada.

\section{BIBLIOGRAFIA}

Bruno, Giuliana. 2002. Atlas of Emotion. Londres, Nova Iorque: Verso.

Carroll, Noël. 1982. "The Future Of Allusion: Hollywood in the Seventies (and Beyond)". October 20: 51-81.

Christopher, Nicholas. 1997. Somewhere in the Night: Film Noir and the American City. Nova Iorque: Free Press.

Conard, Mark T. ed. 2007. The Philosophy of Neo-Noir. Lexington: University Press of Kentucky.

Cook, Pam. 1985. The Cinema Book. Londres: BFI.

Elsaesser, Thomas. 2004. "The Pathos of Failure: American Films in the 1970s: Notes on the Unmotivated Hero." In The Last Great American Picture Show: New Hollywood Cinema in the 1970s, editado por Noel King, Alexander Horwath e Thomas Elsaesser. Amsterdão: Amsterdam University Press. 279-292. 
Farber, Stephen. 1969-1970. "End of the Road?" Film Quarterly 23.2: 3-16.

Frasca, Giampiero. 2001. Road Movie: Immaginario, Genesi, Struttura E Forma Del Cinema Americano on the Road. Turim: UTET libreria.

Hayward, Susan. 2006. Cinema Studies: The Key Concepts. Londres, Nova Iorque. Routledge.

Johnson, Williams. 1974. "Badlands by Terrence Malick." Film Quarterly 27.3: 43-46.

Lefebvre, Martin. 2006. Landscape and Film. Nova Iorque: Routledge. $51,153$.

Rosário, Filipa. 2009. "The Status of Success in the Post-Modern Road Movie Character". In Success and Failure - Essays from the 29th Apeaa Conference, editado por David Callahan, Anthony Barker e Maria Aline Ferreira, 171-178. Aveiro: Universidade de Aveiro.

Schneekloth, Lynda H. 1996. "The Frontier Is Our Home.” Journal of Architectural Education 49.4: 210-225.

Schrader, Paul. 1990. Schrader on Schrader. Editado por Kevin Jackson. Londres: Faber and Faber. 33-37.

Sklar, Robert. 1976. Movie-Made America: A Cultural History of American Movies. Nova Iorque: Vintage Books.

Willett, Ralph. 1970. "The American Western: Myth and Anti-Myth." Journal of Popular Culture 4.2: 455-463.

Williams, Raymond. 1973. The Country and the City. Nova Iorque: Oxford University Press.

\section{FILMOGRAFIA}

Alice's Restaurant [longa metragem] Real. Arthur Penn. Elkins Entertainment et al., EUA, 1969. 111 mins.

Badlands [longa metragem] Real. Terence Malick. Warner Bros et al., EUA, 1973. 94 mins.

Bonnie and Clyde [longa metragem] Real. Arthur Penn. Warner Bros, EUA, 1967. 112 mins.

Days of Heaven [longa metragem] Real. Terence Malick. Paramount Pictures, EUA, 1978. 94 mins.

Easy Rider [longa metragem] Real. Dennis Hopper. Columbia Pictures Corporation et al., EUA, 1969. 95 mins. 
Gun Crazy [longa metragem] Real. Joseph H. Lewis. King Brothers Productions, EUA, 1950. 86 mins.

Little Caesar [longa metragem] Real. Mervyn LeRoy, First National Pictures, EUA, 1930. 79 mins.

Midnight Cowboy [longa metragem] Real. John Schlesinger. Jerome Hellman Productions et al, EUA, 1969. 113 mins.

Natural Born Killers [longa metragem] Real. Oliver Stone. Warner Bros. et al, EUA, 1994. 118 mins.

Scarface [longa metragem] Real. Howard Hawks, The Caddo Company, EUA, 1932. 93 mins.

Sommaren med Monika [longa metragem] Real. Ingmar Bergman. Svensk Filmindustri, Suécia, 1953. 96 mins.

The Public Enemy [longa metragem] Real. William Wellman. Warner Bros. et al., EUA, 1931. 138 mins.

They Live by Night [longa metragem] Real. Nicholas Ray. RKO Radio Pictures, EUA, 1948. 95 mins.

True Romance. [longa metragem] Real. Tony Scott. Morgan Creek Productions et al, EUA, 1993. 120 mins.

Two-lane Blacktop [longa metragem] Real. Monte Hellmann. Michael Laughlin Enterprises, EUA, 1971. 102 mins.

Vanishing Point [longa metragem] Real. Richard C. Sarafian. Cupid Productions et al., EUA, 1971. 99 mins. 